\title{
Model Test Study on the Influence of Train Speed on the Dynamic Response of an X-Section Pile-Net Composite Foundation
}

\author{
Shanshan Xue $\mathbb{D}^{1,2}$ Yumin Chen $\mathbb{D}^{1,2}$ and Hanlong Liu $\mathbb{D}^{1,2,3}$ \\ ${ }^{1}$ Key Laboratory of Ministry of Education for Geomechanics and Embankment Engineering, Hohai University, \\ Nanjing 210024, China \\ ${ }^{2}$ College of Civil and Transportation Engineering, Hohai University, Nanjing 210024, China \\ ${ }^{3}$ Key Laboratory of New Technology for Construction of Cities in Mountain Area, Chongqing University, \\ Chongqing 400044, China
}

Correspondence should be addressed to Yumin Chen; ymch@hhu.edu.cn

Received 17 April 2019; Accepted 16 July 2019; Published 6 August 2019

Academic Editor: Nuno M. Maia

Copyright (C) 2019 Shanshan Xue et al. This is an open access article distributed under the Creative Commons Attribution License, which permits unrestricted use, distribution, and reproduction in any medium, provided the original work is properly cited.

Based on a large-scale X-section pile-net composite foundation model, we experimentally studied the dynamic characteristics of the pile-net composite foundation under a high-speed railway train load; analyzed the distribution characteristics of the dynamic stress, dynamic displacement, speed, and acceleration of the foundation soil under different train speeds; and investigated the vibration response of the track subgrade foundation system, as well as the distribution characteristics and attenuation pattern of the dynamic stress inside the subgrade foundation under cyclic train loading. The following results are obtained. The peak vertical vibration speed and the peak acceleration attenuate by $90 \%$ and $62.5 \%$, respectively, after passing through the embankment. The vibration velocity increases linearly with the train speed; the ratio of the peak dynamic soil stresses at the top of the piles and between the piles is approximately 3.4. The change in train speed does not have a large influence on the peak dynamic displacement or peak dynamic soil stress. The peak spectral vibration acceleration caused by the train loading is located within the range of medium-to-low-frequency vibrations, and the characteristic frequency corresponds to the passing frequency of the bogies and carriages; as the train speed increases, the peak spectral vibration acceleration increases, and the high-frequency components increase significantly.

\section{Introduction}

Along with the rapid development of the national economy in China, the high-speed railway has been developed rapidly. Because of its characteristics of a long operational cycle and fast train speed, the high-speed railway has much stricter requirements on the settlement control than those of an ordinary railway. The pile-net composite foundation has the advantages of fast construction, low cost, small settlement, and high stability and has thus been widely applied as a ground treatment for high-speed railways in China, such as the Wuhan-Guangzhou, Beijing-Shanghai, and SuiningChongqing high-speed railway lines.

The strengthening performance of the pile-net composite foundation has resulted in its widespread practical application. However, because of its complicated working mechanism under train loading, the studies on this foundation are not adequate at present and have mainly been carried out by means of field testing and laboratory experimentation.

Heck [1] analyzed the mechanism of the train vibration and found that, besides the sleeper-passing frequency, the passing frequency of the wheelsets is also a main frequency that is produced by the train vibration. Takemiya and Bian [2] analyzed the test data of the Shinkansen line with a train speed of $240 \mathrm{~km} / \mathrm{h}$ and concluded that the pulse impact on the subgrade is related to the distance between wheelsets. Bahrekazemi and Bodare [3] analyzed the fundamental dynamic patterns of vibration induced by a train using measurement data. In China, Bo and Ying [4] recorded relevant data for the dynamic response of a subgrade by field measurements of the Datong-Qinhuangdao, 
Chengdu-Kunming, and Baoji-Chengdu railway lines. Chen and Lü Wentian [5] carried out field tests on a roadbridge transition section of the Qinhuangdao-Shenyang passenger railway line and studied the dynamic response under the operation of a high-speed train.

Compared to field testing with its limitations, large-scale model experimentation is an effective approach to study the interaction between the track and subgrade and can satisfactorily reveal the mechanism for the response of the track subgrade foundation of a high-speed railway to train loading. Anderson and Key [6] established a physical model for a $1 \mathrm{~m}$ long, $0.8 \mathrm{~m}$ wide, and $0.6 \mathrm{~m}$ high two-layer railway track ballast bed and studied the dynamic performance of the structure layer material of the ballast bed under longterm repeated loading. Cox et al. [7] conducted a comparative study via laboratory experiments on the different types of floating slab and fastener system and simulated the vibration characteristics of the floating slab under fixedpoint loading by a single-wheel axle load. Using a laboratory 1:2 slab track model, Zhan and Jiang [8] studied the dynamic response (e.g., dynamic stress, dynamic displacement, and propagation of acceleration along the cross section and depth of subgrade) of different structural layers in a ballastless track subgrade system under fixed-point loading. Under a moving train load, the principal stress axis of the soil inside the subgrade rotates, significantly affecting the working performance of the subgrade. Therefore, it is necessary to introduce a moving load into experiments. Momoya et al. [9] conducted a laboratory experiment using a 1:5 ballasted track model and studied the distribution characteristics and settlement development of stress inside the subgrade under a moving load, but the simulated train speed was only $42 \mathrm{~km} / \mathrm{h}$. Al Shaer et al. [10] constructed a $1: 3$ ballasted track model containing three sleepers, adopted an $\mathrm{M}$-shaped wave to represent a bogie load, and studied the relationship between the subgrade settlement and sleeper vibration acceleration. Through experiments using a laboratory $1: 5$ ballasted track model, Ishikawa et al. [11] compared the difference in the stress paths inside the subgrade under two loading scenarios (i.e., fixed-point loading and moving loading) and revealed the rotational characteristics of the principal stress axis under a moving load and its influence on the permanent deformation of the subgrade. Their results showed that a moving load generates a larger permanent deformation of the subgrade. However, the transient dynamic response of a pile-net composite foundation under different actual train speeds has rarely been studied by experiments.

The X-section pile is an irregular pile with an X-shaped cross section. Because of its large perimeter-to-area ratio, the $\mathrm{X}$-section pile can significantly improve the bearing capacity of a single pile without increasing the amount of concrete in it, thus increasing the cost performance [12-14]. The Liu group conducted numerous studies on the load-bearing mechanism of an X-section pipe under static loading [15-17] and its engineering application [18]. Using a large pile foundation model test system, Guang-Chao et al. [19] conducted a dynamic model test of an X-section pile-raft composite foundation in sandy soil, with a focus on the patterns of change in the cumulative settlement, displacement amplitude, dynamic stiffness, and vibration velocity of the $\mathrm{X}$-section pile-raft composite foundation under cyclic loading in the forms of the M-shaped wave and sinusoidal wave that are often used to simulate high-speed train loads.

In this study, according to the typical design working conditions for the pile-net subgrade foundation, as well as the construction standards for a high-speed railway, and using a 1:5 large-scale pile-net composite foundation in a large test tank, we conducted an experimental study on the dynamic response of a track-subgrade-pile-net composite foundation system under train load, with a focus on the analysis of the vibration response of the system as well as the distribution characteristics and attenuation pattern of the dynamic stress inside the subgrade foundation under varying train speeds.

\section{Large-Scale Pile-Net Composite Foundation Model}

2.1. Overview of Model. To ensure the safe and effective operation of high-speed trains, there are strict requirements for the size and filling quality of the various structural layers of high-speed railways. In an earlier stage, we constructed a 1:5 scale high-speed railway subgrade foundation model, with dimensions of $5 \mathrm{~m}, 4 \mathrm{~m}$, and $7 \mathrm{~m}$ in length, width, and height, respectively. The model included, from top to bottom, a track slab, CA mortar, geogrid, surface and bottom layers of the subgrade bed, and foundation. A schematic diagram of the tank section of the model is shown in Figure 1.

The static and dynamic loading control system used in the test is composed of JAW-200K static and dynamic actuators, a load input and control machine, a vibrator controller, and a hydraulic oil source. The maximum test force of the vibrator equipment in this system is $200 \mathrm{kN}$, with a measurement accuracy of $\pm 0.5 \%$. The actuator has a travel distance of $\pm 150 \mathrm{~mm}$, with a displacement readout accuracy of $\pm 1 \%$ and an actuator frequency of 0.1 to $30 \mathrm{~Hz}$. Manufactured by Moog, Inc., Germany, the vibrator controller can set up different vibration waveforms and simulate the cyclic loading of the high-speed railway according to the magnitude of the train load and running speed.

2.2. Foundation Soil and Gravel Cushion Layer. The basic physical parameters of the foundation filling silt adopted in the test were measured by a laboratory consolidation test, with the test results shown in Table 1.

The test model used $28 \mathrm{X}$-section piles of the same material and size. The test pile has a design length of $3950 \mathrm{~mm}$, an open arc spacing of $39.5 \mathrm{~mm}$, a circumscribed circle radius of $76 \mathrm{~mm}$, and an open arc angle of $90^{\circ}$. When the foundation soil was filled and compacted to a height of $0.887 \mathrm{~m}$ from the bottom of the tank, the X-section piles were buried and laid out in a quincunx shape with a pile spacing of $600 \mathrm{~mm}$. To ensure perpendicularity during the laying out, the piles were secured with scaffolding and then filled and compacted layer by layer according to the filling requirements. 


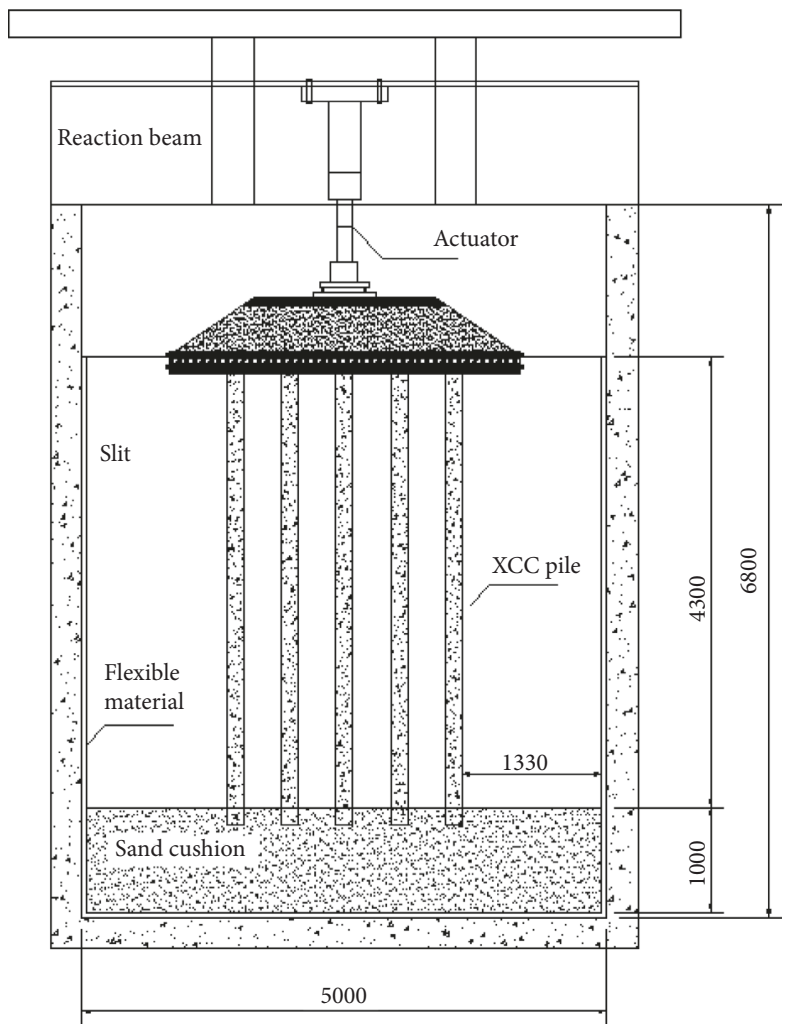

FIGURE 1: Schematic diagram of tank section of the model (unit: $\mathrm{mm}$ ).

TABLE 1: Basic physical indexes of silt.

\begin{tabular}{lcccccc}
\hline Water content (\%) & Unit weight $\left(\mathrm{kN} / \mathrm{m}^{3)}\right.$ & Void ratio & Liquid limit (\%) & Plastic limit (\%) & Plasticity index & Liquid limit index \\
\hline 27.8 & 18.6 & 0.817 & 31.0 & 24.1 & 6.9 & 0.56 \\
\hline
\end{tabular}

Graded gravels were used for the surface layer of the subgrade bed, group A and B fillers were used for the bottom layer of the subgrade bed, and well-graded unweathered gravels or gravel fillers, with a maximum particle size of smaller than $25 \mathrm{~mm}$, were used for the cushion layer. Approximately $10-12 \%$ stone powder or fine particles were blended in the gravels for filling after mixing well. The tensile yield strength of the geogrid used in the pile-net composite foundation is $30.0 \mathrm{kN} / \mathrm{m}$, as shown in Figure 2 .

Considering the dynamic response characteristics of the $\mathrm{X}$-section pile-net composite foundation, we installed in the model test a complete set of dynamic and static test instruments, including displacement gauge, dynamic pressure box, speedometer, accelerometer, and pore pressure gauge, to measure the vibration displacement, dynamic earth pressure, velocity, and acceleration at different locations. The specific layout is shown in Figure 3. Figure 3(a) is the front view, and Figure 3(b) is the top view.

2.3. Loading Method and Design. Different train speeds were simulated by controlling the loading frequency of the actuators. The actuators were equipped with load transducers that monitored the loads of the actuators in real time. The wheel-track load generated by the interaction of the wheel shaft of the train and the track was transferred to the track structure and subgrade through the fastener system. According to field measurement data, the wheel-track load of an operating train is transferred in the form of a dynamic load similar to an M-shaped wave to the foundation of the embankment. Therefore, an M-shaped wave was also adopted for loading in the test, with the load waveform shown in Figure 4. The M-shaped wave shown in the figure is the dynamic load of a train with a speed of $300 \mathrm{~km} / \mathrm{h}$ and an axle load of $10 \mathrm{kN}$. This waveform was fitted using a 3rd-order Fourier series according to the variation pattern and periodic characteristics of the time-history curve. Let $t$ be the running time of the train and $F(t)$ be the equation of the force applied by the actuator. The expression is shown in equation (1):

$$
\begin{aligned}
F(t)= & a_{0}+a_{1} \cos \left(\frac{2 \pi n t}{T}\right)+b_{1} \sin \left(\frac{2 \pi n t}{T}\right)+a_{2} \cos \left(\frac{4 \pi n t}{T}\right) \\
& +b_{2} \sin \left(\frac{4 \pi n t}{T}\right)+a_{3} \cos \left(\frac{6 \pi n t}{T}\right)+b_{3} \sin \left(\frac{6 \pi n t}{T}\right),
\end{aligned}
$$

where $T$ is the vibration period of the actuator load and $a_{\mathrm{n}}$ and $b_{\mathrm{n}}$ are constants obtained based on the actual parameters of a train. 


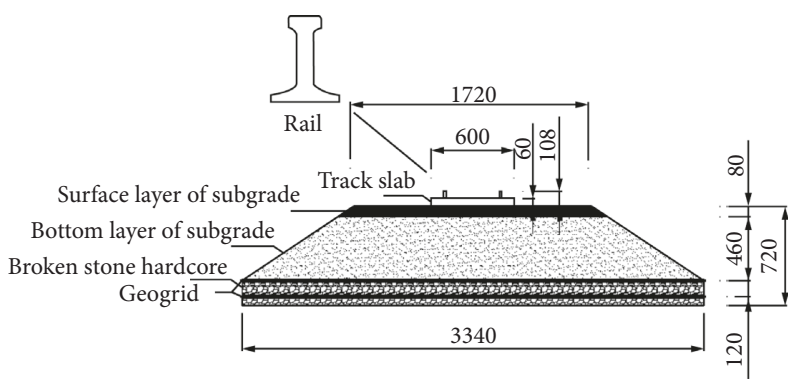

FIGURE 2: Schematic diagram of the embankment section (unit: $\mathrm{mm}$ ).

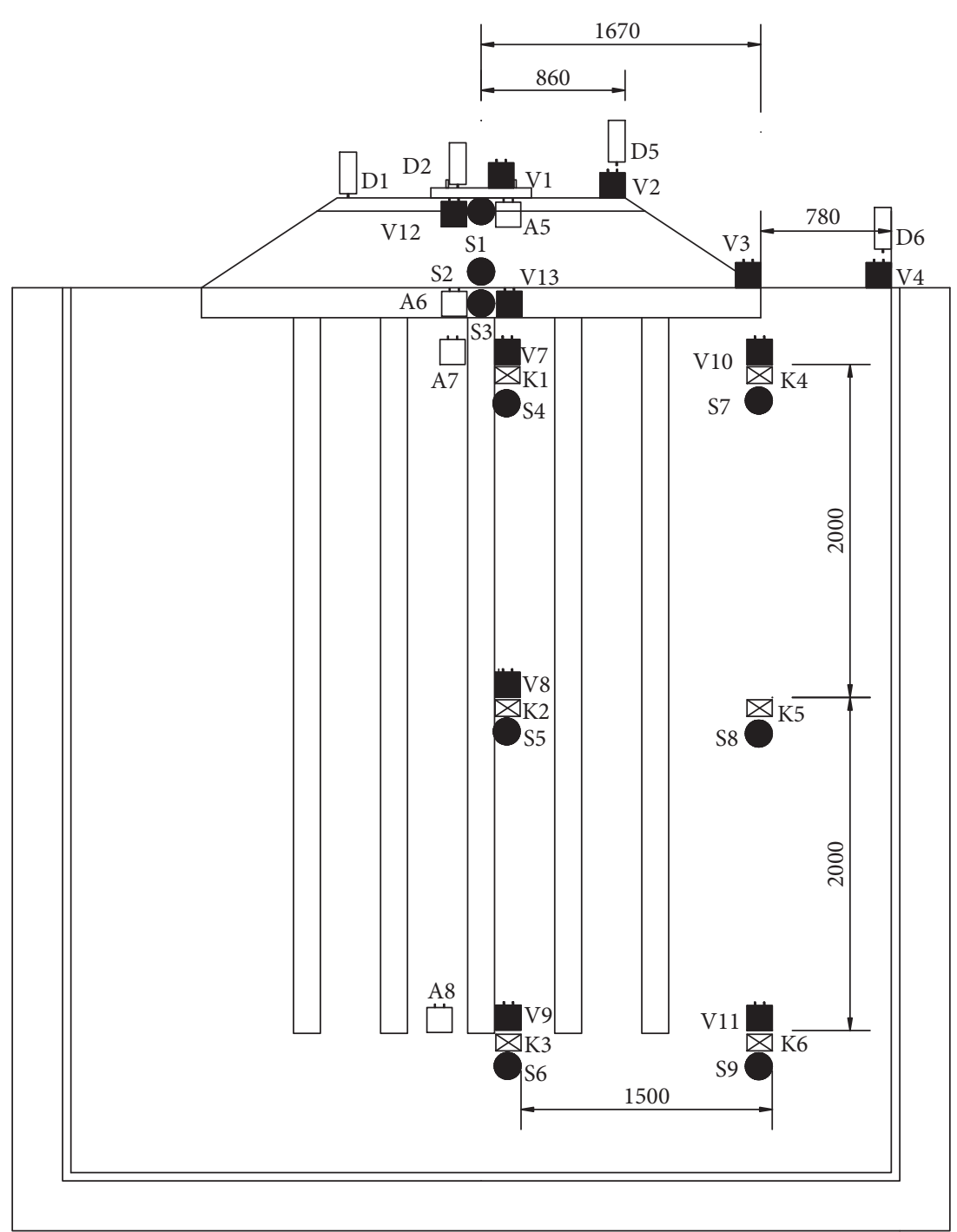

(a)

FIgURe 3: Continued. 


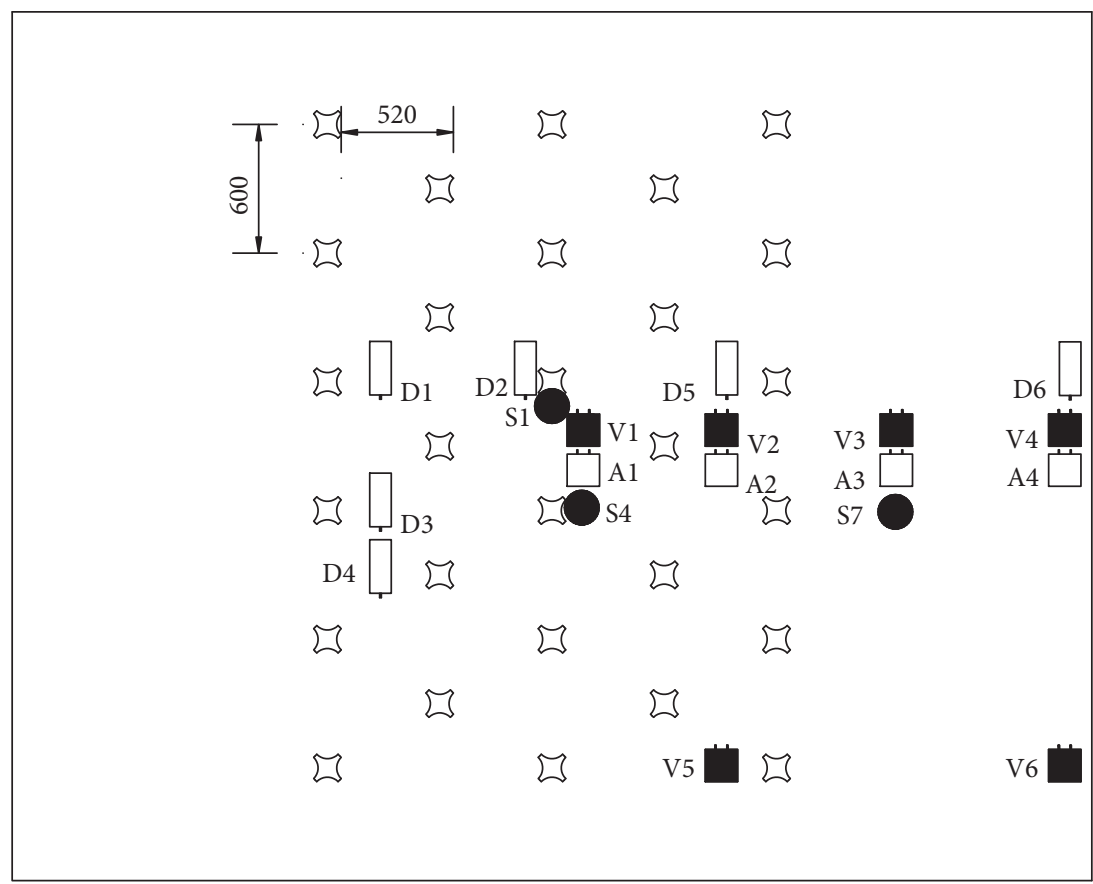

Speedometer $(\mathrm{V})$

Accelerometer (A)

Displacement gauge (D) $\bigotimes \quad$ Pore pressure gauge (K)

Dynamic pressure box $(\mathrm{S})$

(b)

Figure 3: Layout of test instrument (unit: mm): (a) front view; (b) top view.

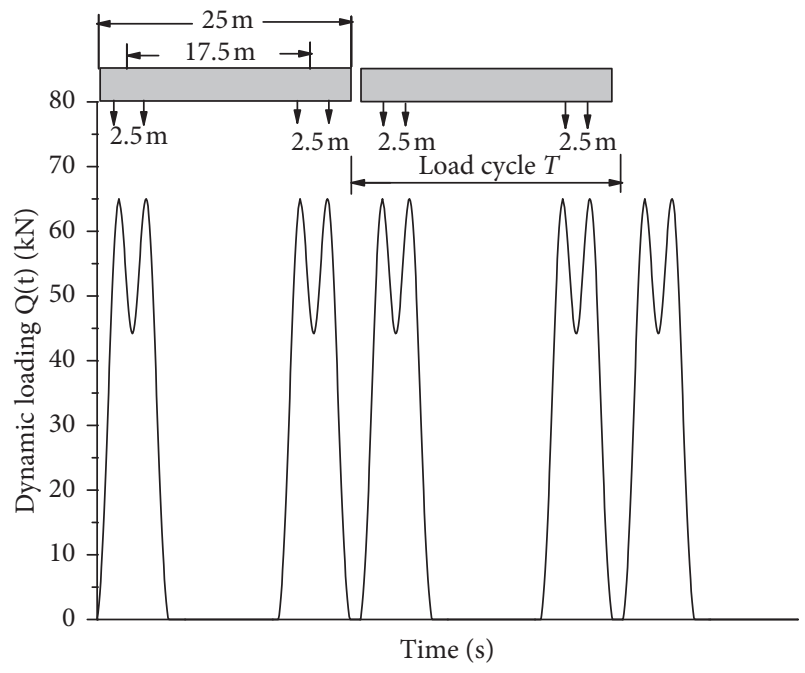

Figure 4: "M"-shaped wave.

The train simulated in this test refers to the main type of CRH3/CRH380 D-series high-speed train operated on the high-speed railway in China. The applied force is the load from the four pairs of wheels of the adjacent bogies of adjacent carriages. The time for passing through the distance of a $2.5 \mathrm{~m}$ bogie is two load cycles. The magnitude of the train load and the running speed is reflected through the load output and frequency of a servo vibrator. The relationship between the train speed and loading frequency is shown in Table 2.

\section{Test Working Conditions and Result Analysis}

3.1. Analysis of Vertical Velocity. Taking a train speed of $300 \mathrm{~km} / \mathrm{h}$ as an example, the time-history response curves of the vertical vibration velocities at different locations of the $\mathrm{X}$-section pile-net composite foundation system are shown in Figure 5.

Under the cyclic load of an M-shaped wave, the timehistory response curve of the velocity of the entire composite foundation exhibits significant periodicity with the cyclic loading process, and the frequency of its velocity response is consistent with the frequency of the cyclic loading.

At the surface and bottom layers of the subgrade bed, the time-history response curves of the velocity induced by the cyclic loading exhibits a significant $M$ shape and, as the depth increases, the amplitude of the M-shaped velocity gradually decreases. Therefore, the dynamic cyclic load induced by the operating train has an important influence on the embankment, and the vibration response of this region is mainly caused by the dynamic load of the train wheel shaft. As they propagate to the foundation, the various reflected waves gradually account for a certain percentage of the total, causing the response waveform to be insignificant.

Figure 5 shows that the response of the velocity at the surface layer of the subgrade bed in the embankment is 
TABLE 2: Train speed and frequency.

\begin{tabular}{lcccc}
\hline Actuator frequency & Two peak period $(\mathrm{s})$ & Corresponding train speed $(\mathrm{km} / \mathrm{h})$ & Two trough periods $(\mathrm{s})$ & Carriage cycle $(\mathrm{s})$ \\
\hline 18 & 0.056 & 160 & 0.173 & 0.142 \\
22 & 0.045 & 200 & 0.111 & 0.455 \\
28 & 0.036 & 250 & 0.095 & 0.357 \\
33 & 0.030 & 300 & 0.080 & 0.303 \\
39 & 0.026 & 350 & 0.256 \\
\hline
\end{tabular}

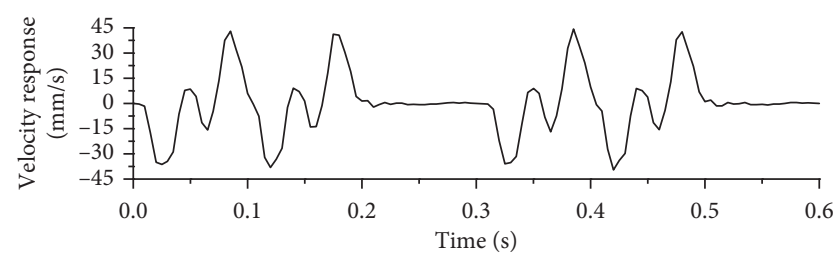

(a)

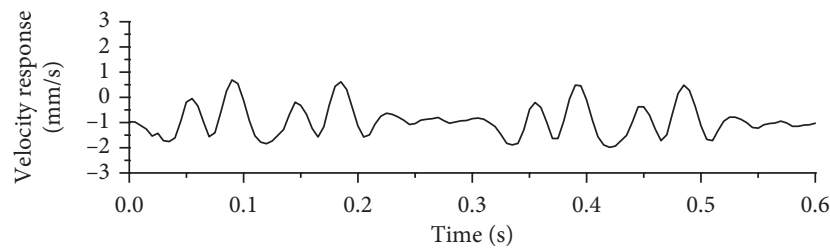

(c)

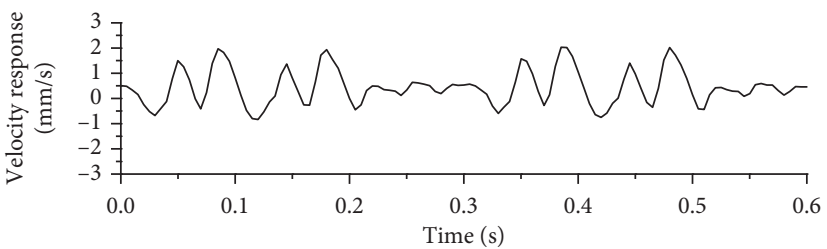

(b)

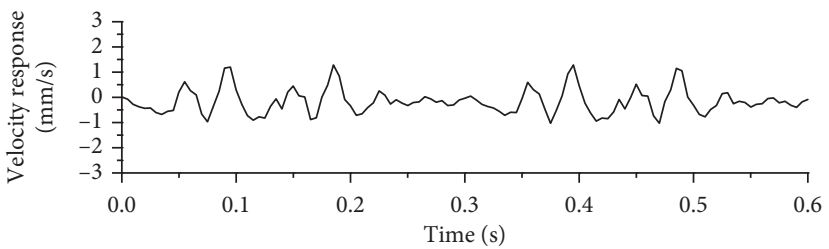

(d)

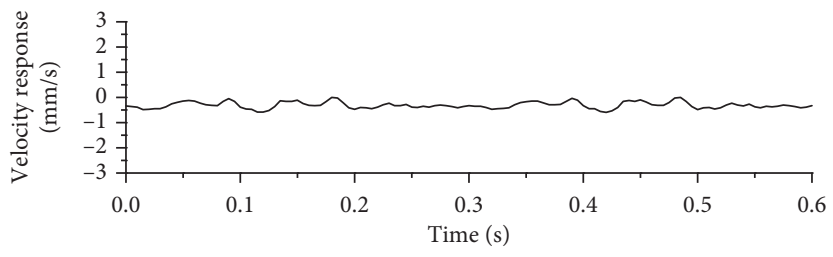

(e)

Figure 5: Vertical velocity with respect to time: (a) track slab; (b) surface layer of subgrade; (c) bottom layer of subgrade; (d) surface layer of foundation; (e) bottom layer of foundation.

mainly caused by the cyclic dynamic load of the train, and it is relatively consistent with the waveform of the loading wave but without the influence of a large number of reflected waves in the foundation soil. Hence, it can better assist in the study of the relationship between the velocity response and the train speed. Therefore, the peak responses of the vertical velocity at the surface layer of the subgrade bed under different train speeds are averaged for analysis. Under different train speeds, the velocity responses of the X-section pile-net composite foundation at different depths are shown in Figure 6. We can see that, with the track slab plane as the $0 \mathrm{~m}$ depth, $1 \mathrm{~m}$ is the surface layer of the subgrade. Under different train speeds, the vibration velocity of the foundation soil rapidly attenuates as the depth increases, and the maximum vibration response occurs at the surface layer of the subgrade bed. It can be seen that, within the depth of $1 \mathrm{~m}$, i.e., within the embankment, the dynamic velocity attenuates by approximately $90 \%$, indicating that the embankment has a very good reduction effect on the propagation of the vibration load, while the attenuation rate of the speed, after it reaches the foundation, decreases.
Figure 7 shows the relationship curve between the response of the vertical velocity at the track slab and the train speed. The peak response of the velocity at the track slab under three different train speeds is shown. The distribution of the scattered points reveals that the peak response of the vibration velocity at the track slab and the train speed are linearly related. As the train speed increases from $160 \mathrm{~km} / \mathrm{h}$ to $350 \mathrm{~km} / \mathrm{h}$, the peak response of the vibration velocity increases from $22.99 \mathrm{~mm} / \mathrm{s}$ to $46.00 \mathrm{~mm} / \mathrm{s}$, an increase of $100 \%$.

The distribution of the vertical vibration velocity response of the track under train operation along the transverse direction of the track is shown in Figure 8. We can see that, in the whole system, the track structure that is closest to the actuator exhibits the most intense vibration response. With a train speed of $350 \mathrm{~km} / \mathrm{h}$, the peak vibration velocity reaches $43.78 \mathrm{~mm} / \mathrm{s}$, while the maximum vibration velocity of the subgrade structure is only $1.02 \mathrm{~mm} / \mathrm{s}$. The vibration of the subgrade system gradually attenuates going farther away from the vibration source, and the vibration velocity at the bottom layer of the subgrade bed as well as within the range of the lower foundation is at a relatively low level and with a 


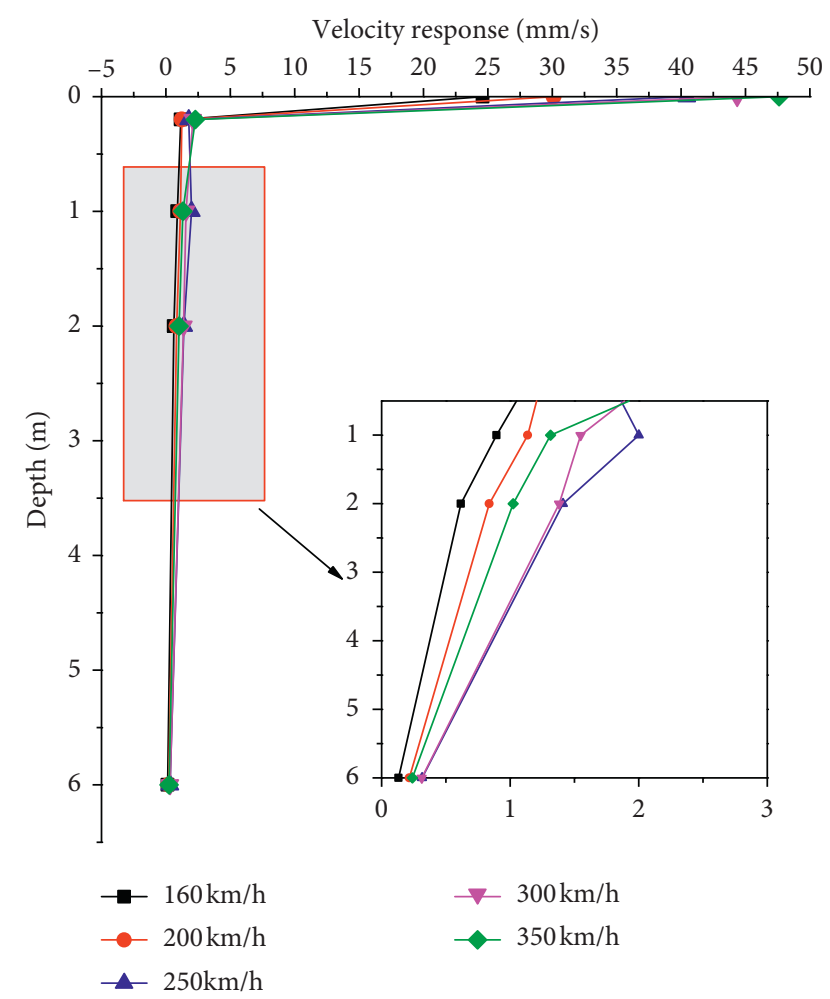

Figure 6: Vertical velocity with respect to depth.

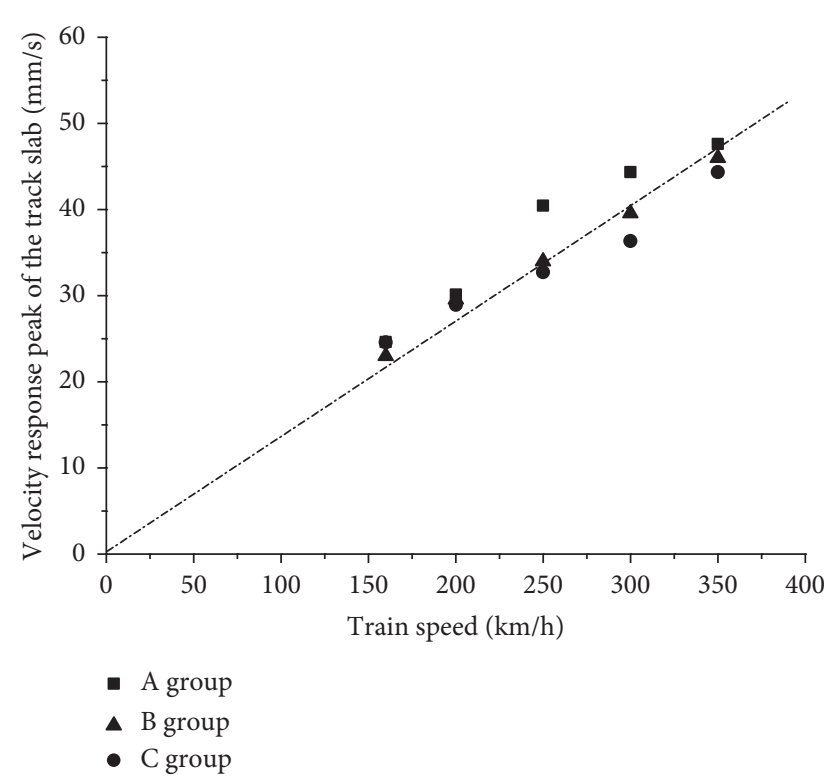

FIGURE 7: Vertical velocity with respect to train speed.

significantly slow attenuation rate, indicating that the subgrade bed has a significant reduction effect on the vertical vibration.

3.2. Analysis of Dynamic Earth Pressure. Figure 9 shows time-history curves of the dynamic soil stress at the pile top and between piles when the train speed is $300 \mathrm{~km} / \mathrm{h}$. The wave is affected by the embankment and hence attenuates during

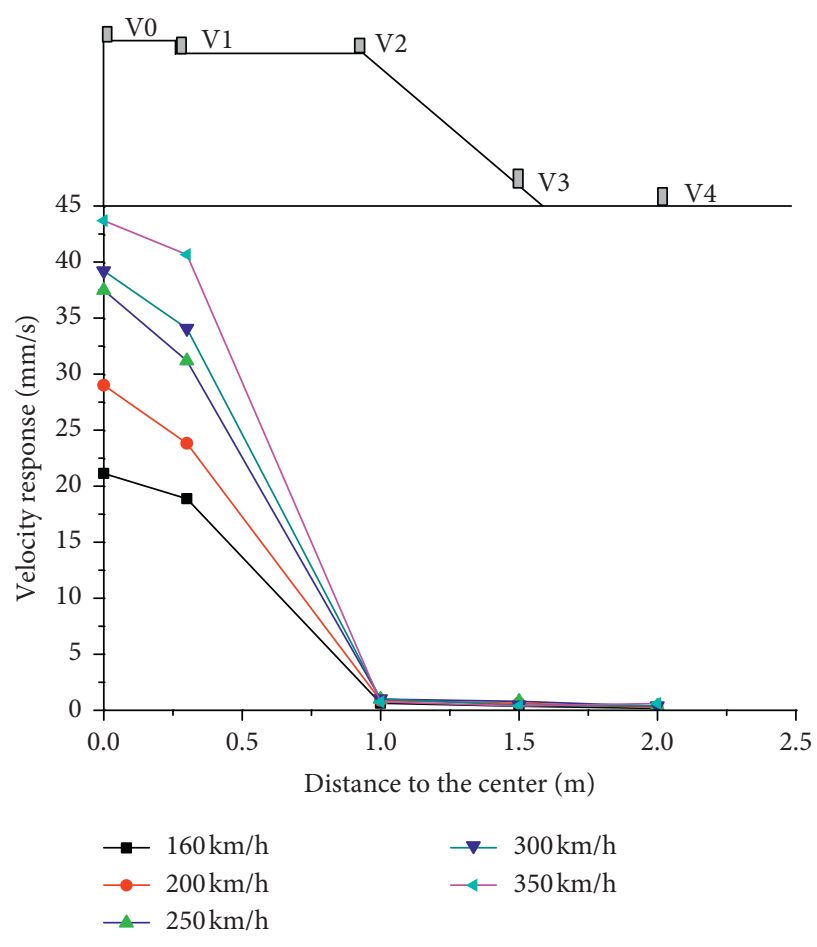

FIgURE 8: Vertical velocity with respect to horizontal dimension.

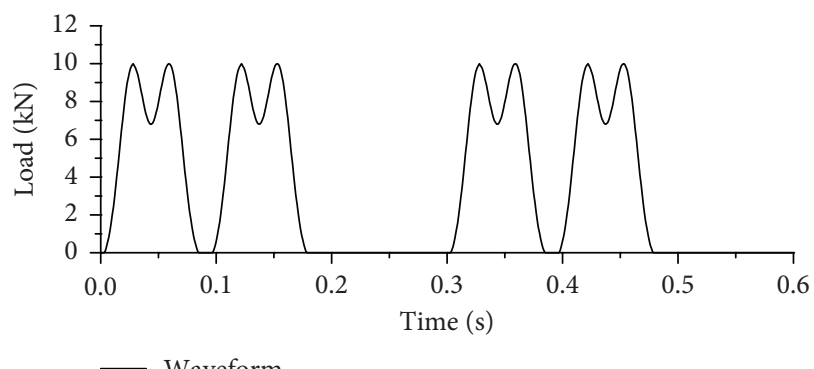

(a)

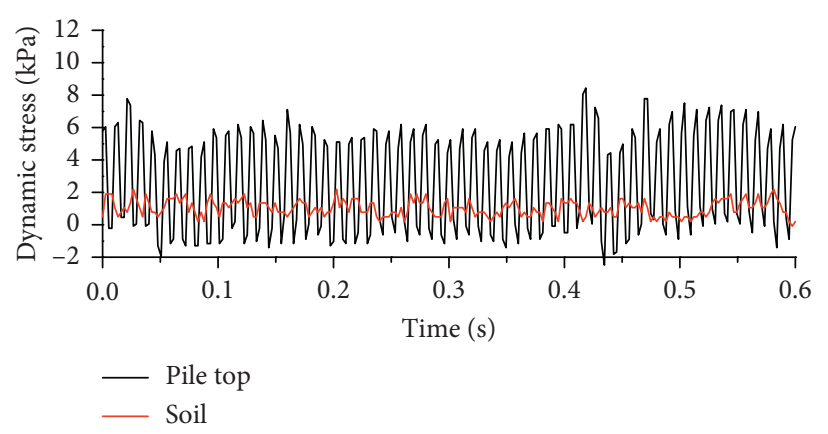

(b)

FIgURE 9: Dynamic stresses of pile and soil with respect to time.

the propagation process, causing the waveform characteristics of the M-shaped wave to have already been significantly weakened when it reaches the surface of the foundation. We can see that the stress at the pile top is greater than the dynamic stress of the soil between piles, and the soil arch has a 
significant influence on the distribution of the dynamic stress. In the soil arch region, a greater dynamic load is transferred above the top of the pile. The average of the peak dynamic stresses at the pile top is approximately $6.2 \mathrm{kPa}$, which is 3.4 times the average of the peak dynamic earth pressure (approximately $1.8 \mathrm{kPa}$ ) on the soil between the piles.

Figure 10 shows relationship curves of the changes in the peak dynamic stresses at the pile top and in the soil between the piles of the foundation and the train speed. We can see that, under the vibration load of the high-speed train, the load carried at the pile top in the foundation is much larger than that by the soil between the piles.

Although the vibration frequency of the dynamic load increases as the train speed increases, the influence of the train speed on the response of the dynamic stress is weak. This is likely because the wave gradually attenuates in the process of reaching the foundation through the subgrade bed, and its effect gradually decreases.

3.3. Analysis of Dynamic Displacement. Figure 11 shows the time-history response curve of the dynamic displacement on the track surface under different train speeds. We can see that the change in the train speed does not have a large influence on the peak transient dynamic displacement response on the track surface. A comparison of dynamic displacement responses under different train speeds reveals that the faster the train speed, the more intense and shorter the induced vibration. This is because the faster the train speed, the higher the dynamic loading frequency. When the train speed is not high $(160 \mathrm{~km} / \mathrm{h})$, the timehistory curve between the peak displacements attenuates. When the train speed reaches $250 \mathrm{~km} / \mathrm{h}$, the displacement time history does not significantly attenuate but instead gradually fluctuates with time. In fact, the attenuation process is not completed.

3.4. Analysis of Acceleration. Figure 12 shows the timehistory curve of the acceleration at different locations in the pile-net composite foundation when the train speed is $300 \mathrm{~km} / \mathrm{h}$. We can see that the vibration close to the actuator has a relatively large amplitude. As the distance from the vibration source increases, the amplitude of the acceleration gradually decreases, and the high-frequency components attenuate especially rapidly. Because the track slab is relatively close to the subgrade bed, its peak acceleration is approximately $80 \mathrm{~mm} / \mathrm{s}^{2}$. After passing through the track slab, the waveform at the surface layer of the subgrade bed is not as significant as that at the track slab.

It can be clearly seen from Figure 12 that, after passing through the subgrade bed, the peak acceleration decreases from $80 \mathrm{~mm} / \mathrm{s}^{2}$ to $30 \mathrm{~mm} / \mathrm{s}^{2}$; that is, it attenuates by $62.5 \%$. This is mainly because the high-frequency components are absorbed due to the damping effect of the soil in the embankment, while the attenuation of the low-frequency components is relatively slow. When reaching the bottom layer of the foundation, due to the influence of the reflected waves, the M-shaped waveform has essentially disappeared. As a result, only a simple harmonic oscillation curve is

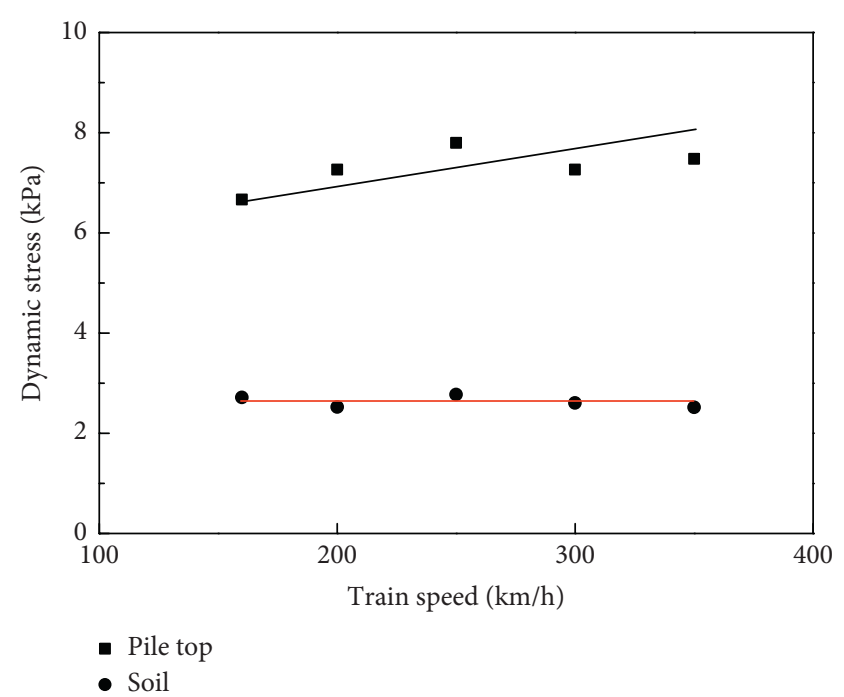

FIgURE 10: Relationship curves between dynamic stress responses of soil at pipe top and between piles and the train speed.

presented, and the amplitude of the acceleration vibration is only $2 \%$ of that at the surface layer of the foundation. As the depth increases, the peak acceleration responses of the M-shaped waveform at different locations do not appear at the same time. This is because it takes time for the wave to propagate, causing some lag in the acceleration response.

Figure 13 shows a spectral curve of the vertical acceleration at different locations from the vibration source when the train speed is $300 \mathrm{~km} / \mathrm{h}$. We can see that the frequency is distributed in the range of $0-100 \mathrm{~Hz}$ and is mainly concentrated between 10 and $50 \mathrm{~Hz}$, making it low-frequency vibrations. As the distance from the vibration source increases, the maximum vibration accelerations at different locations are $43.52 \mathrm{~mm} / \mathrm{s}^{2}, \quad 40.82 \mathrm{~mm} / \mathrm{s}^{2}, \quad 31.52 \mathrm{~mm} / \mathrm{s}^{2}$, $3.52 \mathrm{~mm} / \mathrm{s}^{2}$, and $0.14 \mathrm{~mm} / \mathrm{s}^{2}$. It can be seen that, as the distance from the vibration source increases, the amplitude of the acceleration generally attenuates. The high-frequency component is relatively rich at locations close to the vibration source, and the width of the spectrum gradually decreases when moving away from the vibration source. The most significant frequency band becomes that of the low frequency because the high-frequency components attenuate faster than the low-frequency components.

We can see from the peaks in Figure 13 that the four characteristic frequencies with the largest contributions to the vibration are $19.9 \mathrm{~Hz}, 23.3 \mathrm{~Hz}, 29.9 \mathrm{~Hz}$, and $33.2 \mathrm{~Hz}$. Among them, $33.2 \mathrm{~Hz}$ corresponds to the actuator frequency. At the measurement site of the track slab, the frequency of the ground vibration caused by the train is distributed within $50-85 \mathrm{~Hz}$ and relatively rich in the main frequency.

Figure 14 shows the time-history curve of the acceleration at the surface layer of the foundation under different train speeds. We can clearly see that as the train speed increases, the high-frequency components significantly increase. When the train speed is $160 \mathrm{~km} / \mathrm{h}$, the peak acceleration at the surface layer of the foundation is $3.59 \mathrm{~mm} / \mathrm{s}^{2}$, and when the train velocity increases to $200 \mathrm{~km} / \mathrm{h}$, the peak acceleration at the surface layer of the foundation reaches $7.24 \mathrm{~mm} / \mathrm{s}^{2}$ 


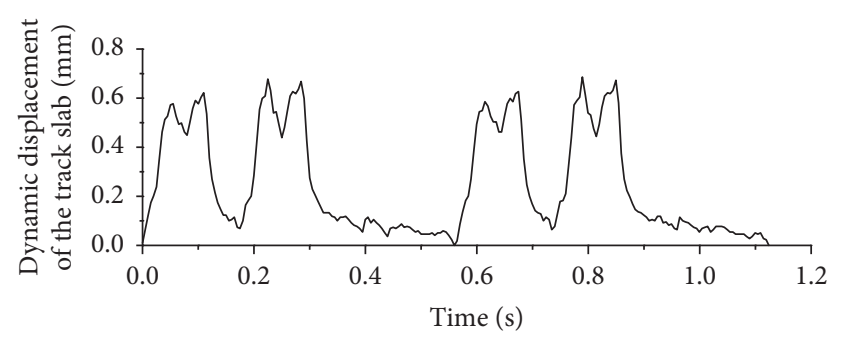

$-160 \mathrm{~km} / \mathrm{h}$

(a)

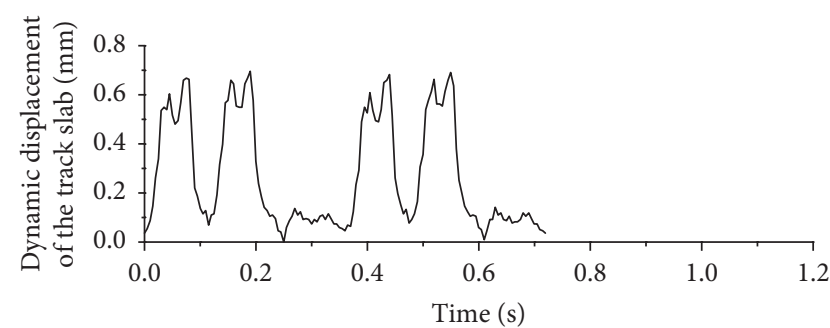

$-250 \mathrm{~km} / \mathrm{h}$

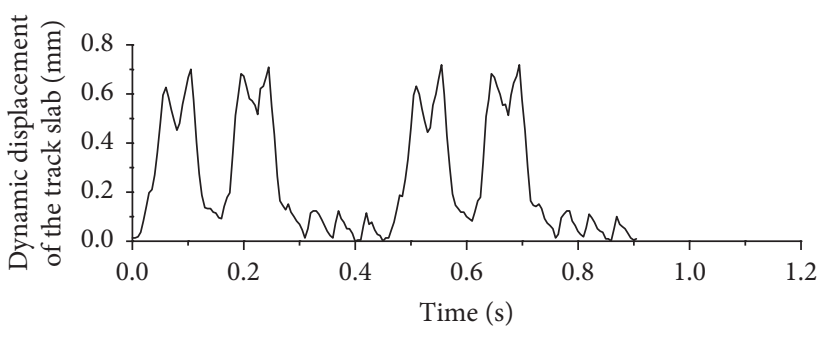

$-200 \mathrm{~km} / \mathrm{h}$

(b)

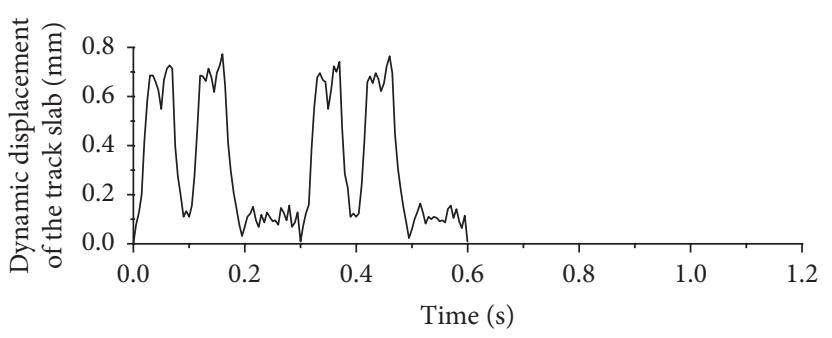

(d)

- $300 \mathrm{~km} / \mathrm{h}$

(c)

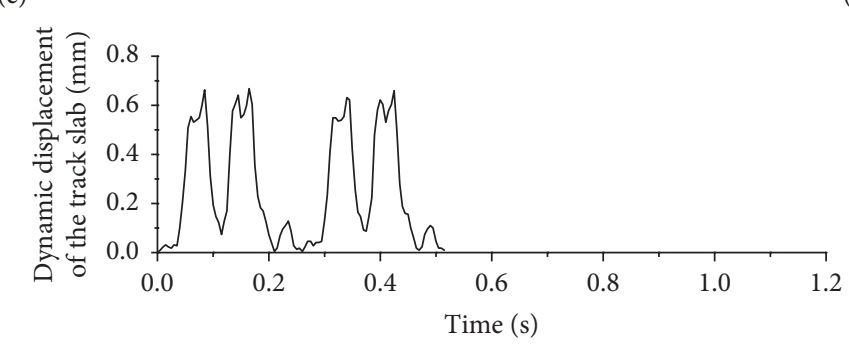

$-350 \mathrm{~km} / \mathrm{h}$

(e)

FIgURE 11: Dynamic displacement of track with respect to time.

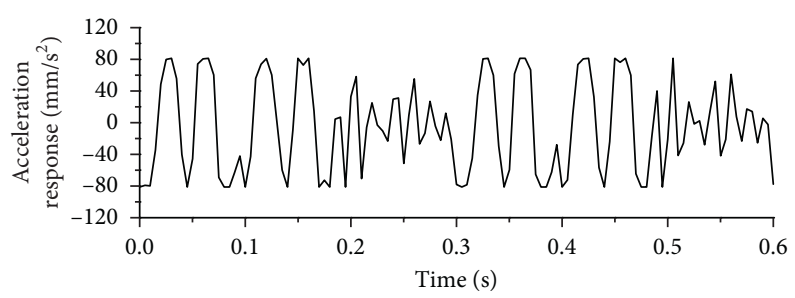

(a)

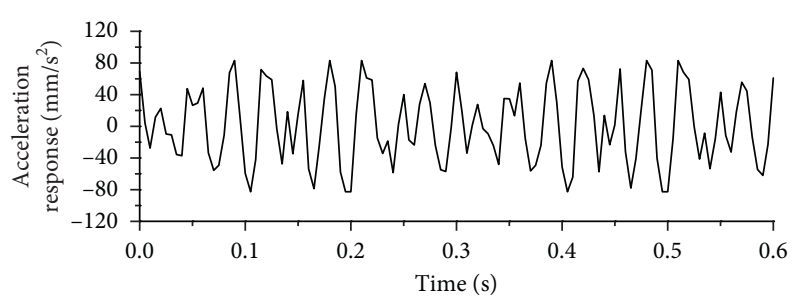

(c)

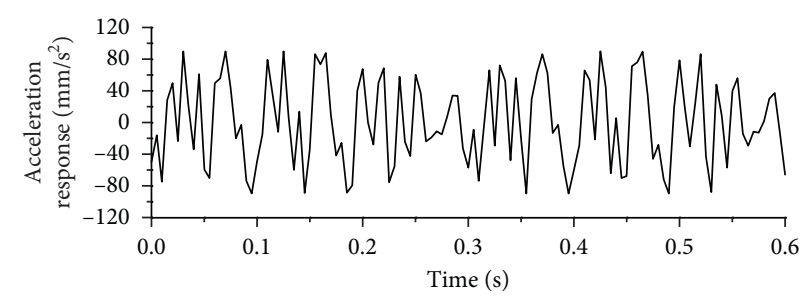

(b)

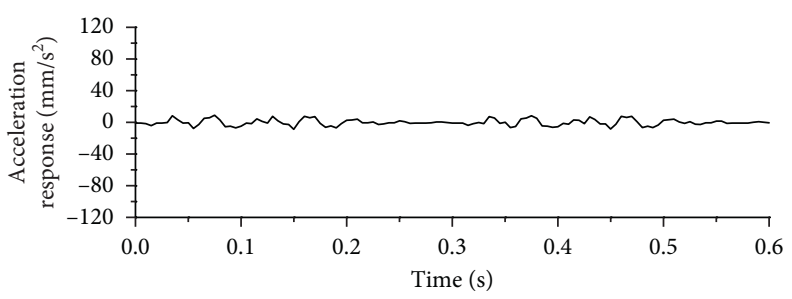

(d)

FIGURE 12: Acceleration at different layers with respect to time: (a) track slab; (b) surface layer of subgrade; (c) bottom layer of subgrade; (d) surface layer of foundation. 


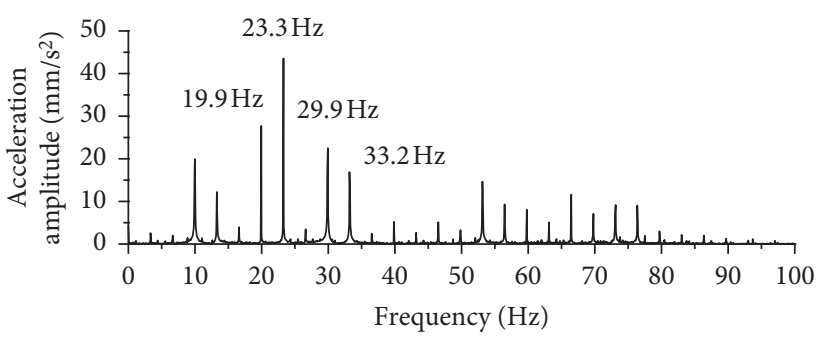

(a)

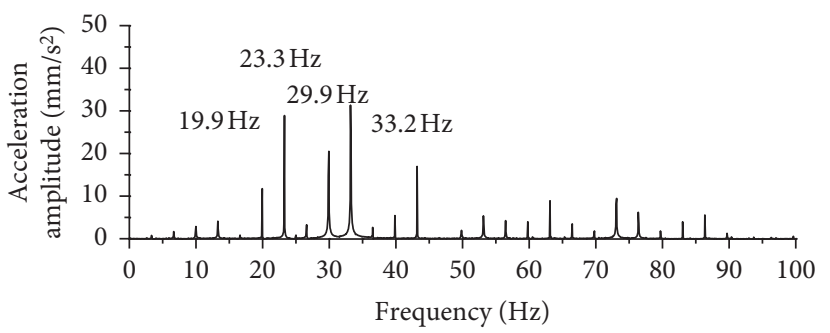

(c)

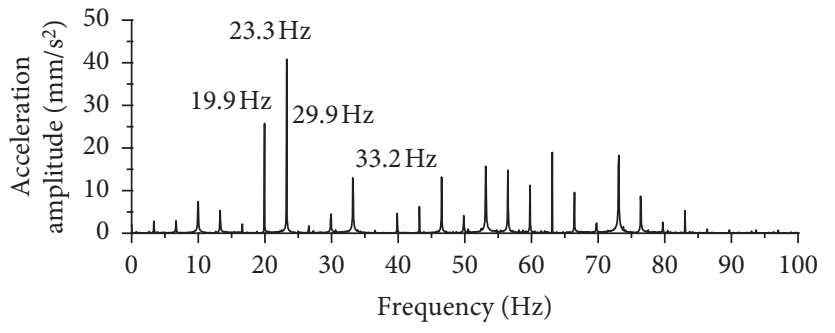

(b)

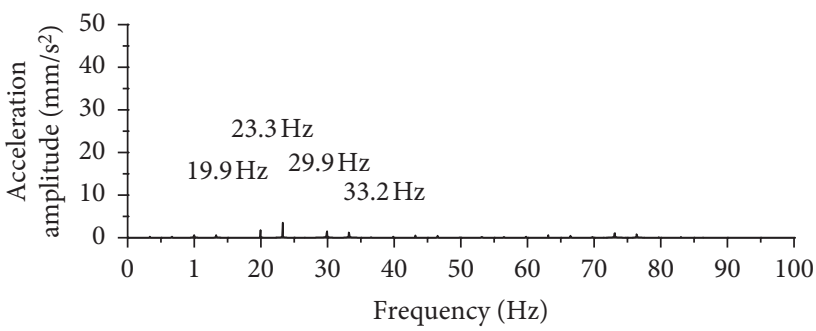

(d)

FiguRE 13: Spectral curve of acceleration at different locations: (a) track slab; (b) surface layer of subgrade; (c) bottom layer of subgrade; (d) surface layer of foundation.

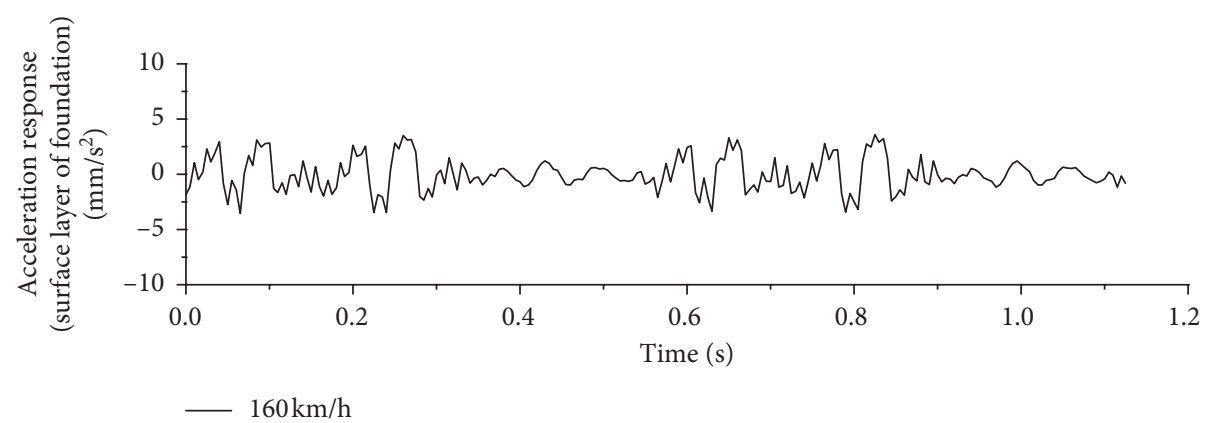

(a)

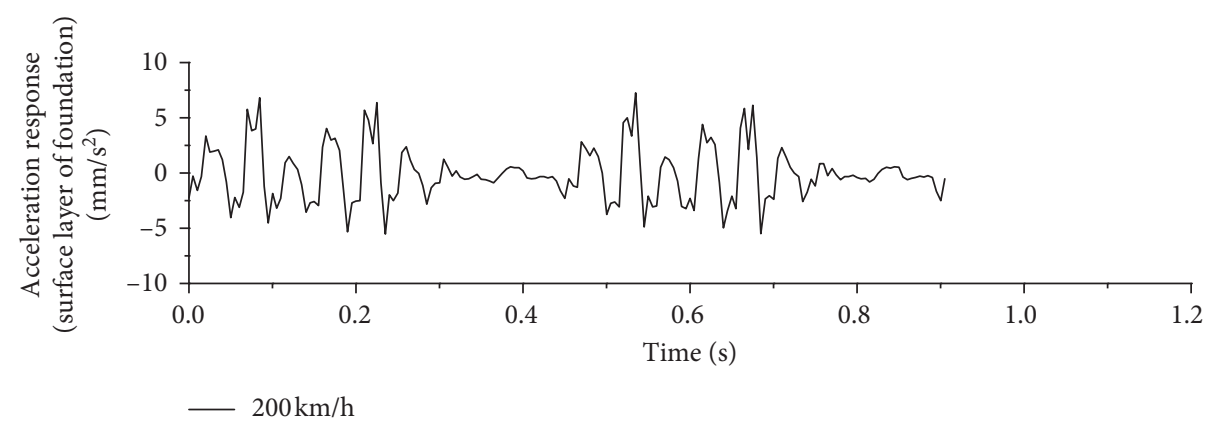

(b)

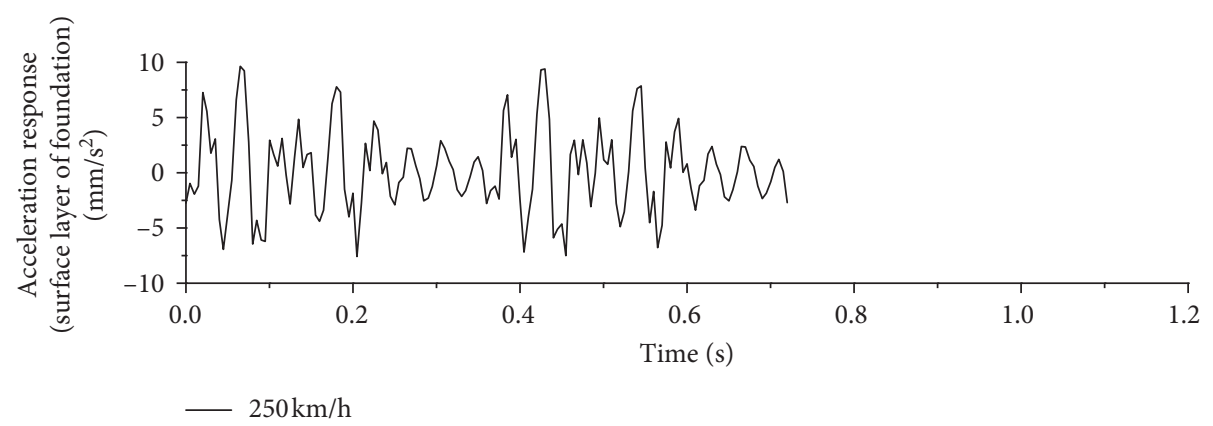

(c)

FIgURE 14: Continued. 


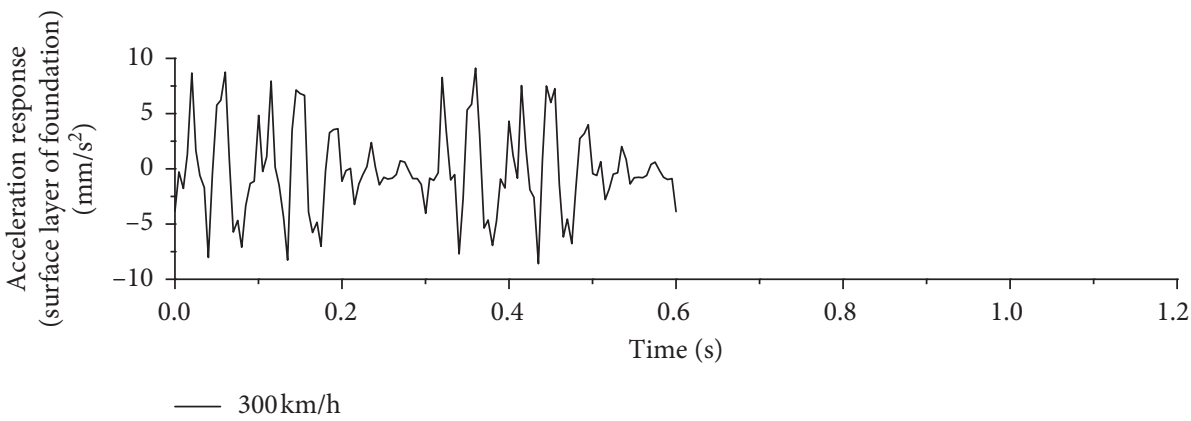

(d)

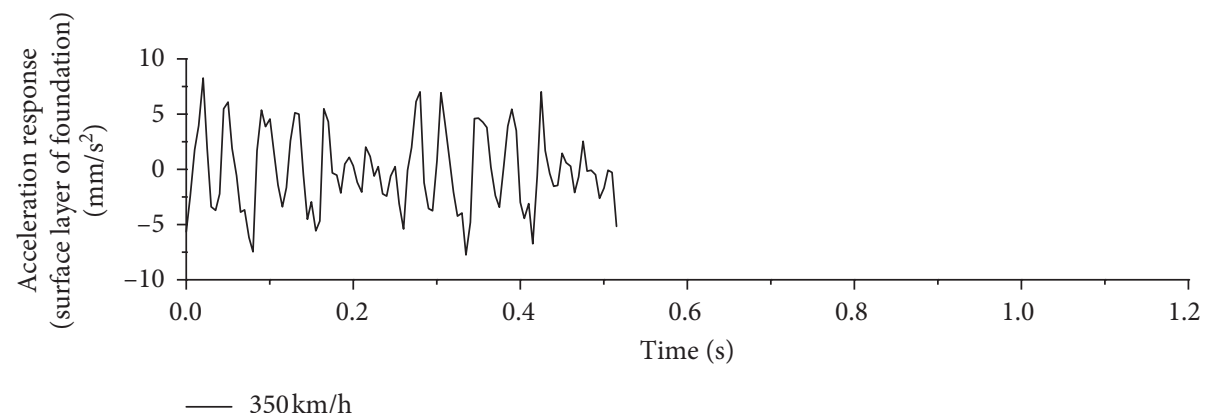

(e)

FIgUre 14: Acceleration under different speeds with respect to time.

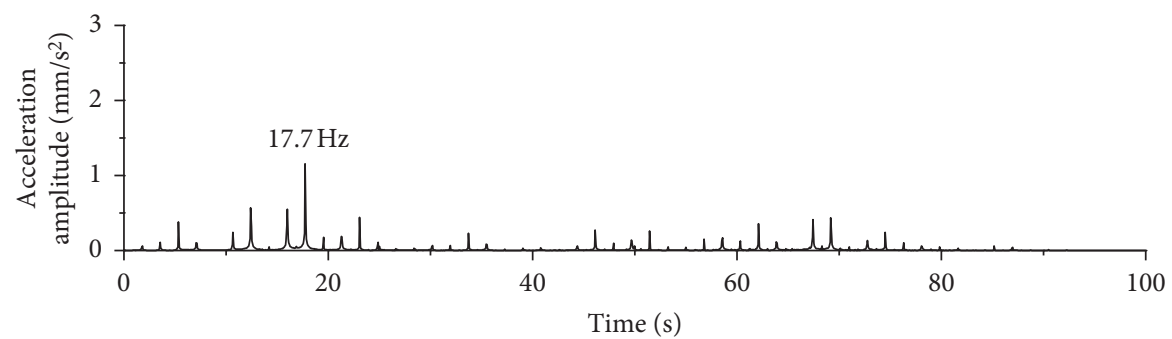

$-160 \mathrm{~km} / \mathrm{h}$

(a)

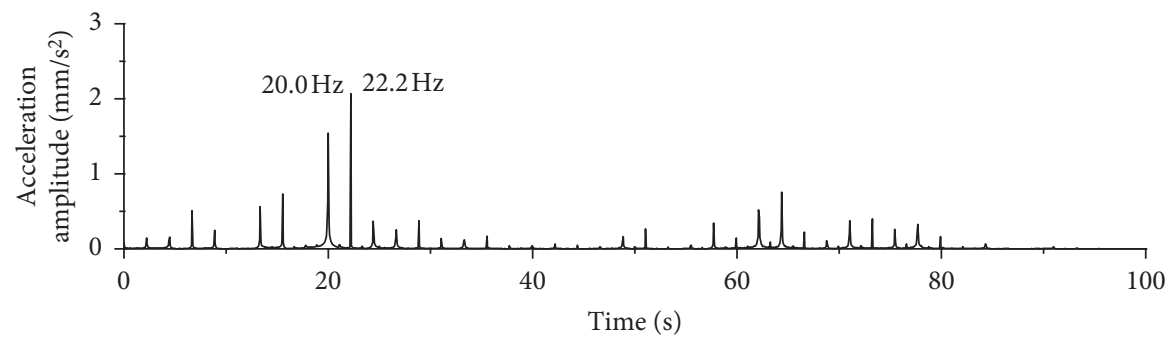

(b)

FIgURE 15: Continued. 


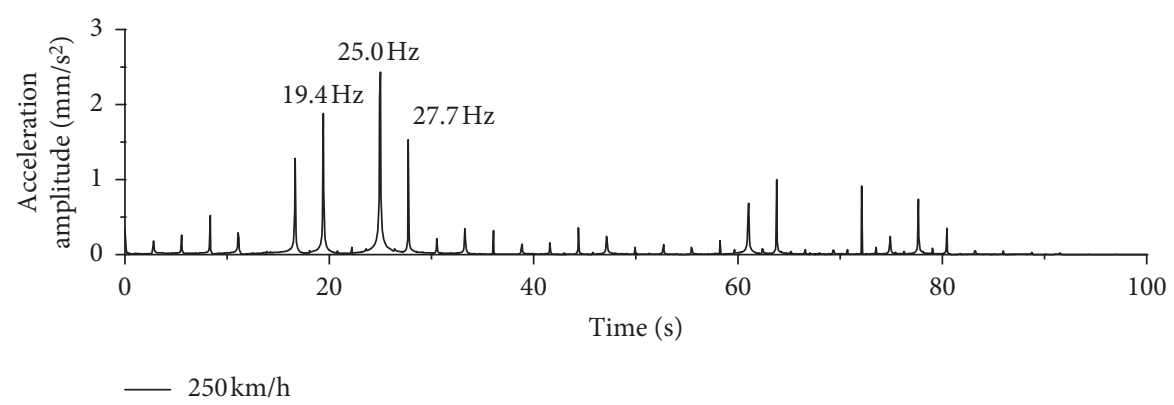

(c)

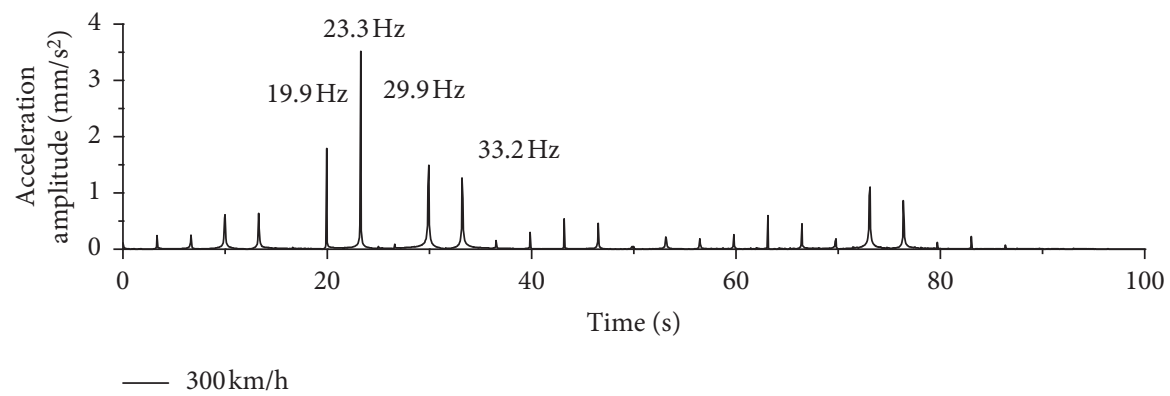

(d)

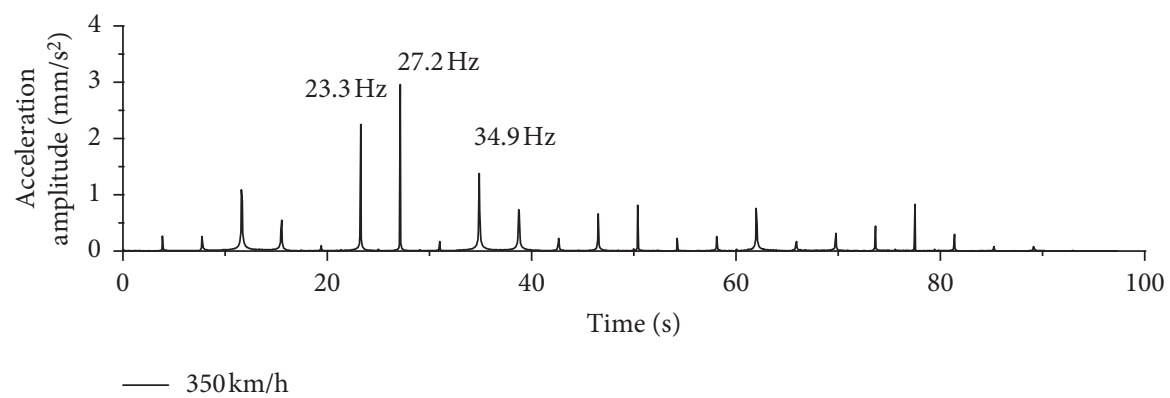

(e)

FIgURE 15: Spectrum curve of acceleration under different speeds.

(approximately double). However, when the train speed reaches $250 \mathrm{~km} / \mathrm{h}$, the increase on the peak is negligible. Because the increase in the train speed is achieved by increasing the vibration frequency, the superposition of the surrounding reflected waves in this process likely produces a counteraction to the vibration of the subgrade foundation, explaining this result.

Figure 15 shows the spectral curve of the acceleration at the surface layer of the foundation under different train speeds. We can see that the ground vibration caused by the train is mainly contributed by relatively low-frequency components (mainly below $100 \mathrm{~Hz}$ ). As the train speed increases, the amplitude of the acceleration increases, and the base frequencies of the vibration also gradually increase. $17.7 \mathrm{~Hz}$ in the base frequencies when the train velocity is $160 \mathrm{~km} / \mathrm{h}, 22.2 \mathrm{~Hz}$ when the train speed is $200 \mathrm{~km} / \mathrm{h}, 27.7 \mathrm{~Hz}$ when the train speed is $250 \mathrm{~km} / \mathrm{h}, 33.2 \mathrm{~Hz}$ when the train speed is $300 \mathrm{~km} / \mathrm{h}$, and $38.8 \mathrm{~Hz}$ when the train speed is $350 \mathrm{~km} / \mathrm{h}$ are all the vibration frequency of the actuator under the current working condition.
As the train speed increases, the peak spectral vibration acceleration response also increases, and the frequency corresponding to the peak spectral vibration acceleration also gradually moves to a medium frequency as the train speed increases. The higher the train speed, the richer the frequency components of the ground vibration.

\section{Conclusions}

In this study, by conducting a large-scale dynamic model test on an X-section pile-net composite foundation under different train speeds, we can draw the following conclusions:

(1) The response of the vertical dynamic velocity is the largest at the surface layer of the embankment and attenuates by approximately $90 \%$ in the embankment. The speed rapidly attenuates as the depth increases; the vibration gradually attenuates as the distance from the vibration source increases. At the bottom layer of the subgrade bed and in the range of 
the lower foundation, the attenuation rate significantly decreases, and the vibration velocity is linearly related to the train speed.

(2) Inside the pile-net foundation, the peak dynamic stress at the top of the pile is 3.4 times than that in the soil between piles, and the dynamic stress attenuates with the depth.

(3) The change in train speed does not have a large influence on the peak transient dynamic displacement response at the surface of the track; after passing through the subgrade bed, the peak vertical acceleration decreases from approximately $80 \mathrm{~mm} / \mathrm{s}^{2}$ to $30 \mathrm{~mm} / \mathrm{s}^{2}$, attenuating by $62.5 \%$. This is mainly because the high-frequency components are absorbed due to soil damping effects, and the lowfrequency components attenuate relatively slowly. The foundation vibration caused by the train is a lowfrequency vibration, and the subgrade foundation has an attenuation impact on the high-frequency vibration; the vibration gradually decreases as the distance from the vibration source increases and increases as the train speed increases.

\section{Data Availability}

The data used to support the findings of this study are available from the corresponding author upon request.

\section{Conflicts of Interest}

The authors declare that there are no conflicts of interest regarding the publication of this paper.

\section{Acknowledgments}

This project was supported by the Funds for International Cooperation and Exchange of the National Natural Science Foundation of China (Grant no. 51420105013).

\section{References}

[1] M. A. Heckl, "Railway noise-can random sleeper spacings help," Acta Acustica United with Acustica, vol. 81, no. 6, pp. 559-564, 1995.

[2] H. Takemiya and X. Bian, "Substructure simulation of inhomogeneous track and layered ground dynamic interaction under train passage," Journal of Engineering Mechanics, vol. 131, no. 7, pp. 699-711, 2005.

[3] M. Bahrekazemi and A. Bodare, "Effects of lime-cement soil stabilization against train induced ground vibrations," in Proceedings of the 3rd International Specialty Conference on Grouting and Ground Treatment, New Orleans, LA, USA, February 2003.

[4] L. Bo and C. Ying, "Dynamic analysis on subgrade of high speed railways in geometric irregular condition," Journal of the China Railway Society, vol. 21, pp. 84-88, 1999.

[5] X. Chen and W. Y. Lü Wentian, "Study on the dynamic response of high speed railway bridge-subgrade transition section," Journal of Vibration and Shock, vol. 25, pp. 95-98, 2006.
[6] W. F. Anderson and A. J. Key, "Model testing of two-layer railway track ballast," Journal of Geotechnical and Geoenvironmental Engineering, vol. 126, no. 4, pp. 317-323, 2000.

[7] S. J. Cox, A. Wang, C. Morison, P. Carels, R. Kelly, and O. G. Bewes, "A test rig to investigate slab track structures for controlling ground vibration," Journal of Sound and Vibration, vol. 293, no. 3-5, pp. 901-909, 2006.

[8] Y. Zhan and G. Jiang, "Study of dynamic characteristics of soil subgrade bed for ballastless track," Rock and Soil Mechanics, vol. 31, pp. 392-396, 2010.

[9] Y. Momoya, E. Sekine, and F. Tatsuoka, "Deformation characteristics of railway roadbed and subgrade under moving-wheel load," Soils and Foundations, vol. 45, no. 4, pp. 99-118, 2005.

[10] A. Al Shaer, D. Duhamel, K. Sab, G. Foret, and L. Schmitt, "Experimental settlement and dynamic behavior of a portion of ballasted railway track under high speed trains," Journal of Sound and Vibration, vol. 316, no. 1-5, pp. 211-233, 2008.

[11] T. Ishikawa, E. Sekine, and S. Miura, "Cyclic deformation of granular material subjected to moving-wheel loads," Canadian Geotechnical Journal, vol. 48, no. 5, pp. 691-703, 2011.

[12] G. Q. Kong, X. M. Ding, Y. M. Chen, and G. Yang, "Vertical uplift capacity characteristics and influence factor analysis of cast-in-situ X-section reinforced concrete pile group," Journal of Civil Engineering and Architecture, vol. 29, pp. 49-54, 2012.

[13] M. X. Zhang, H. L. Liu, X. M. Ding, and Z. Q. Wang, "Comparative tests on bearing capacity of cast-in-situ X-shaped concrete piles and circular pile," Chinese Journal of Geotechnical Engineering, vol. 33, pp. 1469-1476, 2011.

[14] Z. Q. Wang, H. L. Liu, M. X. Zhang, J. Yuan, and J. Yong, "Full scale model tests on vertical bearing characteristics of cast-inplace X-section piles," Chinese Journal of Geotechnical Engineering, vol. 32, pp. 903-907, 2010.

[15] Y. Jun, L. Xiao-Min, and L. Han-Long, "Model test study of anti-pulling property of X-shaped concrete pile," Rock and Soil Mechanics, vol. 31, pp. 3430-3434, 2010.

[16] L. Han-Long, L. Zhi-Ping, and W. Xin-Quan, "Study on the geometric characteristics of the cast-in-place X-type vibro-pile section," China Railway Science, vol. 30, pp. 17-23, 2009.

[17] M. X. Zhang, S. M. Ding, and Y. M. Chen, "Test on vertical behavior of cast-in-situ X-shaped concrete pile and its ultimate bearing capacity prediction," Journal of China Coal Society, vol. 36, pp. 267-271, 2011.

[18] L. Han-Long, J. Hui, and D. Xuan-Ming, "Field test research on squeezing effects of X-section cast-in-place concrete pile," Rock and Soil Mechanics, vol. 33, pp. 219-224, 2012.

[19] S. Guang-Chao, L. Han-Long, K. Gang-Qiang, and D. XuanMing, "Model tests on effect of vibration waves on dynamic response of XCC pile-raft composite foundation," Chinese Journal of Geotechnical Engineering, vol. 38, pp. 1021-1029, 2015. 


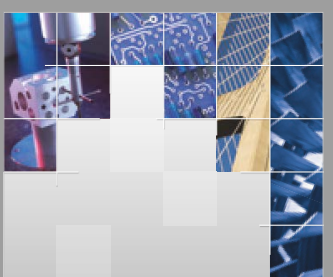

\section{Enfincering}
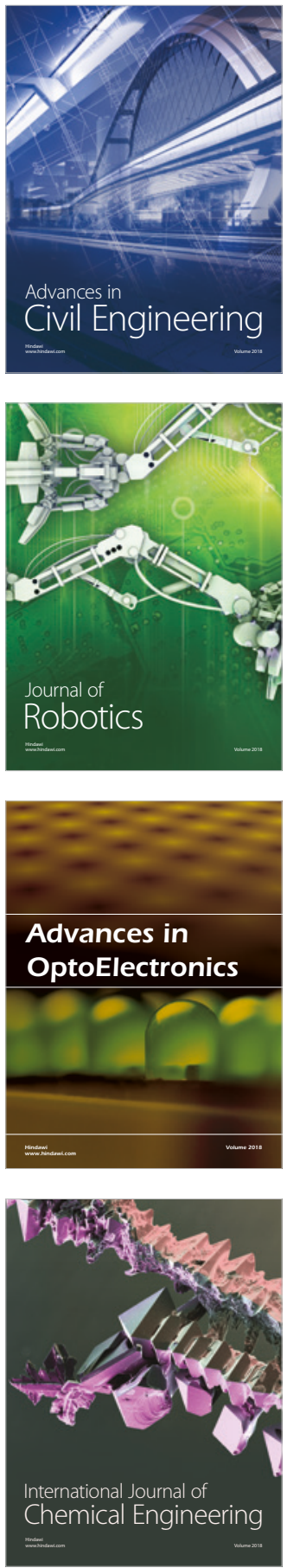

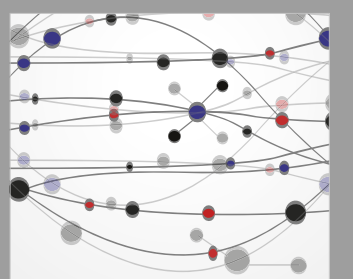

\section{Rotating \\ Machinery}

The Scientific World Journal

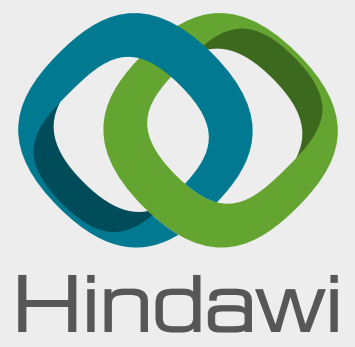

Submit your manuscripts at

www.hindawi.com
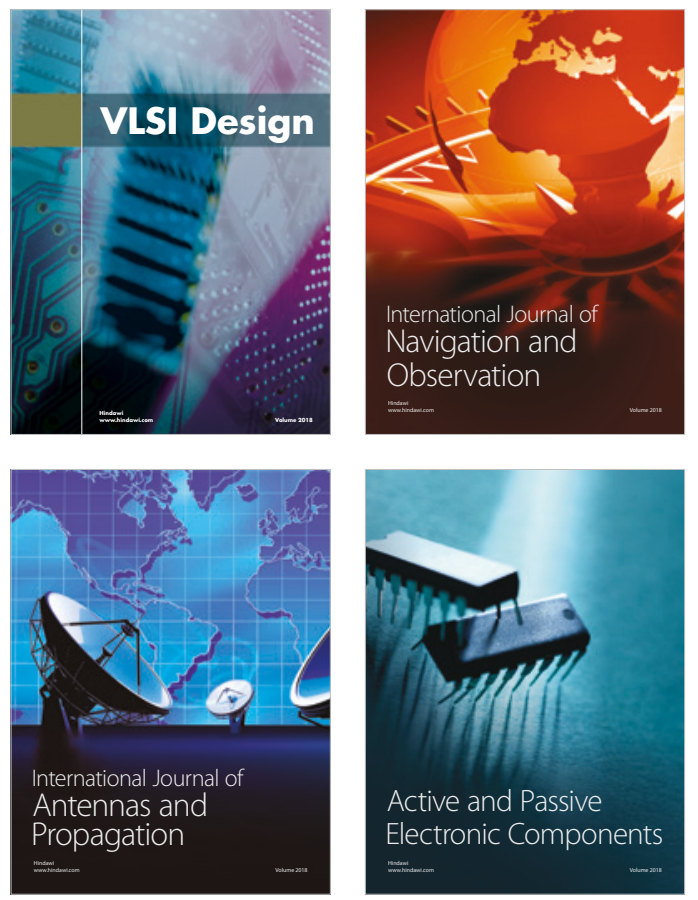
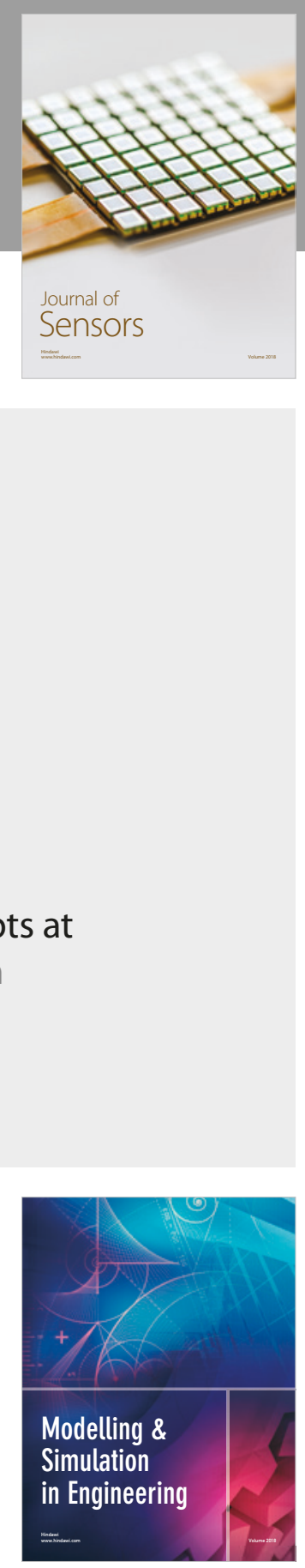

\section{Advances \\ Multimedia}
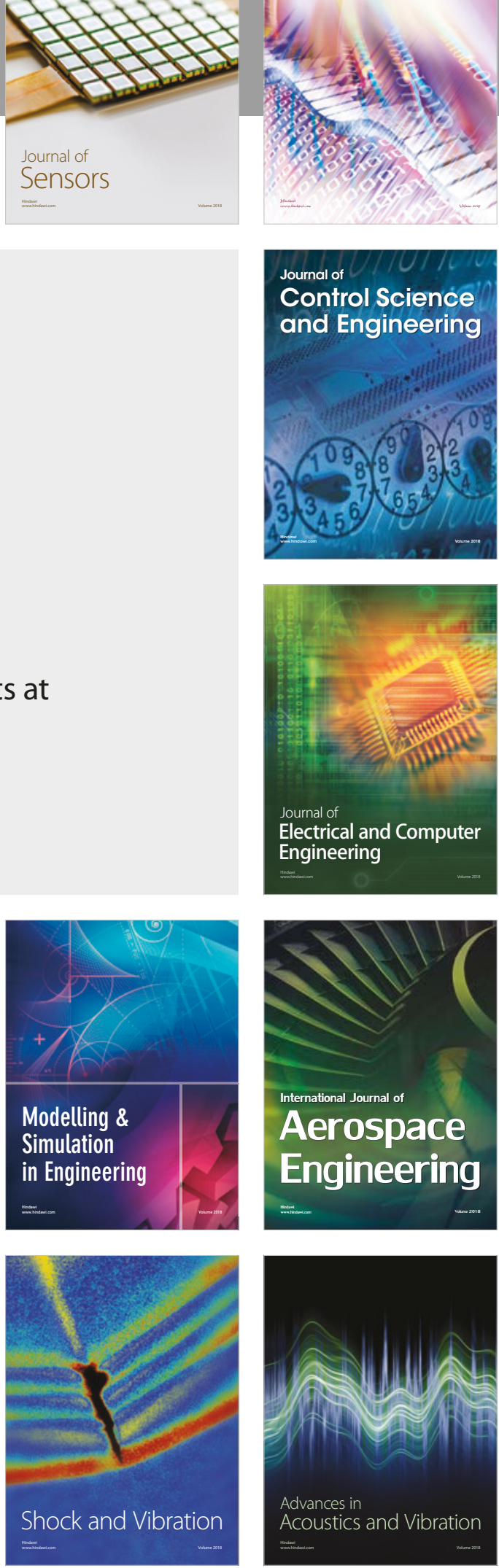